This item was submitted to Loughborough's Research Repository by the author.

Items in Figshare are protected by copyright, with all rights reserved, unless otherwise indicated.

\title{
Me, myself, and future generations: The role of affinity and effectiveness in the creation of consumer environmental stewardship (CENS)
}

PLEASE CITE THE PUBLISHED VERSION

http://dx.doi.org/10.1002/mar.20882

PUBLISHER

(c) Wiley

VERSION

AM (Accepted Manuscript)

\section{PUBLISHER STATEMENT}

This work is made available according to the conditions of the Creative Commons Attribution-NonCommercialNoDerivatives 4.0 International (CC BY-NC-ND 4.0) licence. Full details of this licence are available at: https://creativecommons.org/licenses/by-nc-nd/4.0/

\section{LICENCE}

CC BY-NC-ND 4.0

\section{REPOSITORY RECORD}

Hensen, Niek, Debbie Keeling, Ko de Ruyter, and Martin Wetzels. 2019. "Me, Myself, and Future Generations: The Role of Affinity and Effectiveness in the Creation of Consumer Environmental Stewardship (CENS)". figshare. https://hdl.handle.net/2134/21475. 


\section{Me, Myself and Future Generations: The Role of Affinity and Effectiveness in the Creation of Consumer Environmental Stewardship (CENS)}

Authors: Niek Hensen ${ }^{\mathrm{a}, *}$, Debbie I. Keeling ${ }^{\mathrm{b}}$ Ko de Ruyter $^{\mathrm{c}}$, Martin Wetzels ${ }^{\mathrm{d}}$.

* Corresponding Author.

${ }^{a}$ Ph.D., Maastricht University School of Business and Economics, Department of Marketing \& Supply Chain Management, Tongersestraat 53, 6211 LM Maastricht, P.O. Box 616, 6200 MD Maastricht, The Netherlands

Phone: +31 621297884

Fax: +31 433884918

E-mail: n.hensen@maastrichtuniversity.nl

${ }^{\mathrm{b}}$ Associate Professor of Marketing, Loughborough University, School of Business and Economics, Ashby Road, Loughborough, LE11 3TU, United Kingdom

Phone: +44 1509223117

Email: D.I.Keeling@lboro.ac.uk

${ }^{\mathrm{c}}$ Professor of Marketing, Cass Business School, City University London, 106 Bunhill Row, EC1Y 8TZ London, United Kingdom

Phone:

E-mail: Ko.De-Ruyter.1@city.ac.uk

${ }^{\mathrm{d}}$ Professor of Supply Chain and Marketing Research, Maastricht University School of Business and Economics, Department of Marketing \& Supply Chain Management, Tongersestraat 53, 6211 LM Maastricht, P.O. Box 616, 6200 MD Maastricht, The Netherlands

Phone: +31 433883934

E-mail: m.wetzels@maastrichtuniversity.nl 


\title{
Me, Myself and Future Generations: The Role of Affinity and Effectiveness in the Creation of Consumer Environmental Stewardship (CENS)
}

\begin{abstract}
Policymakers, consumer advocate groups and researchers agree that consumers need to increase their pro-environmental behaviors if a decent standard of living is to be ensured for future generations. Despite high levels of environmental concern consumers still refrain from large scale adoption of pro-environmental behaviors. Social marketers agree that a change in attitudes is not enough to stimulate the necessary behavioral change and are looking for ways to help consumers overcome the costs (e.g., price premiums, inconvenience) that are often associated with pro-environmental behaviors. Currently, consumers often see proenvironmental behavior as a trade-off between short-term personal benefits and longer term collective benefits. The authors contribute to the social marketing literature on proenvironmental behavior by introducing the concept of Consumer Environmental Stewardship (CENS), which centers on the use of intrinsic motivation to stimulate a personal sense of responsibility for the environment. The findings, based on a survey and three experiments, show that the stimulation of consumers' affinity with future generations (AFG) and perceived consumer effectiveness (PCE) can help to promote CENS, which in turn raises proenvironmental behaviors. However, this research also shows that increasing levels of AFG can backfire and result in lower levels of CENS, if consumers experience low levels of PCE.
\end{abstract}

Keywords: consumer environmental stewardship; affinity with future generations; perceived consumer effectiveness; pro-environmental behavior 
Policymakers, consumer advocate groups and researchers agree that the world's resources cannot continue to be (ab)used at the current pace. In an effort to change current consumption patterns, policymakers worldwide have invested in large scale social marketing campaigns over the past decades (Kollmuss \& Agyeman, 2002; Whitmarsh \& O'Neill, 2010). These campaigns have mainly focused on information provision based on the rationale that awareness about environmental problems and knowledge about environmentally friendly alternatives would drive pro-environmental actions (Steg \& Vlek, 2009). The use of financial incentives to stimulate pro-environmental consumer behaviors, e.g., tax reductions on hybrid cars or subsidies for home insulation, have been more effective than information oriented social marketing campaigns alone (European Commission, 2008; OECD, 2011). However, financial rewards lead consumers to think of pro-environmental behaviors as personal optimization problems; when subsidies are absent choices are based on optimizing personal gains, hence, pro-environmental behaviors with a personal cost are avoided (Kouchaki, Smith-Crowe, Brief, \& Sousa, 2013; Tenbrunsel \& Messick, 1999). Despite substantial efforts and higher levels of environmental awareness and concern, recent studies confirm that consumers still refrain from large scale adoption of pro-environmental behaviors (Cleveland, Kalamas, \& Laroche, 2012; Englis \& Phillips, 2013). The behaviors that consumers are willing to adopt, whilst necessary, are not sufficient to bring about real impact for a sustainable future (Thøgersen \& Crompton, 2009). Thus, contemporary societies face the enduring problem of how to increase pro-environmental behaviors to a scale that makes a sustainable future possible.

Within this paper it is posited that recent theorizing on the notion of stewardship could be valuable in addressing this problem. Stewardship is based on the premise that responsible actions bring about long-term benefits for multiple stakeholders and that these must be balanced against self-serving, shorter-term economic goals. Contributing to the literature, 
within this paper the concept of consumer environmental stewardship (CENS) is developed and empirically assessed as a mechanism through which consumers can be stimulated to adopt pro-environmental behaviors that serve long-term collective benefits. CENS is advanced as a means of subjugating short-term personal benefits to serve a higher entity or 'organization', (i.e., the environment), and its current and future beneficiaries, (i.e., society at large and future generations) and develop and validate a scale to measure CENS.

As a second contribution, a set of relevant and theory-based antecedents and consequences of CENS is identified. Previous research has demonstrated that the stimulation of stewardship can be achieved by raising people's affinity with future generations (WadeBenzoni, 2008). Affinity with future generations (AFG) is defined as the extent to which an individual feels empathic towards and connected with future others (Wade-Benzoni, 2008), and serves as one of the main antecedents in this study. Additionally, previous research has shown that perceived consumer effectiveness (PCE), the idea that one can affect the state of the environment as an individual, can stimulate people to subjugate personal interests for the good of the environment (Do Paço, Alves, Shiel, \& Filho, 2013; Moisander, 2007; Webster Jr, 1975). Next to the main effects of these antecedents, the interaction between AFG and PCE on CENS is also examined.

To achieve these contributions, the paper proceeds as follows. The first section concentrates on the development of a conceptual framework with consumer environmental stewardship as the mechanism that translates AFG and PCE into actual behavior. Second, this framework is empirically tested through four studies. Finally, the theoretical and public policy implications of this research are discussed as supported by the emergent theoretical framework. 


\section{Conceptualizing Consumer Environmental Stewardship (CENS)}

Stewardship theorists recognize that there needs to be a balancing between one's own goals and those of the larger entity (Hernandez, 2008). The stewardship concept is multifaceted. It has a moral basis and centers on a feeling of obligation, responsibility and accountability towards a bigger entity that is reflected in the willingness to balance one's own self- or group-interests with the long-term interests of this bigger entity even if this requires some personal sacrifice. As a main premise, stewardship provides a solid and insightful basis for the study of pro-environmental behaviors at the individual level because of three distinctive characteristics. First, stewardship can be explained in terms of felt obligations (especially relational and ideological) without formal written agreements or contracts. Second, based on these obligations, stewardship fundamentally relates to the 'protection' of ongoing long-term social welfare. Third, stewardship allows for people to be temporally and personally detached from the consequences of their stewardship behaviors. That is, they do not necessarily have to be beneficiaries of the resulting collective gains. The stewardship concept is thus adaptable to the intergenerational context of environmental protection for the welfare of society and future generations and in this way suitable for a transition to a consumer context. Based on this, the authors define the concept of consumer environmental stewardship (CENS) as “an individual’s willingness to take personal responsibility for, and balance one's own short-term interests with long-term collective interests of the environment, society and future generations, even if this requires personal sacrifices in consumption decisions".

It has been posited that stewardship is conceptually distinct from other prosocial behaviors, as well as perhaps being broader in its conceptual outlook. For instance, Batson (1987) argues that the experience of empathy will drive self-sacrificial behavior, but that this does not necessarily have beneficial consequences for a collective resource (i.e., like the 
environment). Stewardship focuses on how individuals forego their self-interest for the benefit of a collective interest and, therefore, is a more comprehensive prosocial concept. Furthermore, helping others or actively promoting a good cause (such as responsibility for the environment) does not necessarily imply a longer-term perspective (Hernandez, 2012). Stewardship behaviors are explicitly taking these long term consequences on the welfare of others into account (Donaldson \& Preston, 1995). Such behaviors have been shown to be particularly relevant to social dilemmas that emerge between generations. In these situations behavior is characteristically enacted in the present and consequences will only become apparent in the future. As Hernandez (2012, p. 176) argues, 'individuals can be both temporally and interpersonally removed from the consequences of their stewardship behaviors'. This is particularly applicable to the focus on environmentally responsible behaviors. Furthermore, it is argued that a felt relationship with beneficiaries of stewardship behaviors is based on an emotional bond and taking into account their collective wellbeing.

\section{Antecedents and Consequences of CENS: Hypotheses Development}

A strong affective connection and identification with a bigger entity is a pre-requisite for stewardship (Block, 1993; Davis, Schoorman, \& Donaldson, 1997). People who value behaviors that promote the long-term welfare of others and feel an affective sense of connection with others are more likely to display stewardship (Hernandez, 2012). Whilst it is difficult to create an affective connection between consumers and the environment, one could try to create an emotional bond with the environment's main beneficiaries to increase the relevance of pro-environmental behaviors. Thus, within this paper it is posited that feelings of responsibility for the long-term wellbeing of the environment could be stimulated by creating affinity with future generations (AFG). This "refers to a combination of empathy, perspective taking and perceived oneness, and is a function of the extent to which an individual feels 
empathic toward and connected with future others" (Wade-Benzoni \& Tost, 2009, p. 171). The stimulation of feelings of affinity and identification with future generations has been shown to entice people to make sacrifices in personal interest for the benefit of long-term welfare of others (Wade-Benzoni, 2008). In line with these findings the first hypothesis of this study is:

\section{$\mathrm{H}_{1}$ : Higher affinity with future generations (AFG) leads to higher levels of consumer environmental stewardship (CENS).}

Stewardship research emphasizes the importance of self-efficacy and selfdetermination (Davis et al., 1997; Hernandez, 2012). If a person does not feel that (s)he has the ability to influence a situation or does not have a choice in what to do about it, (s)he will not feel responsible for the outcomes of her/his actions. To encourage consumers to feel responsible for their environmental behaviors one should thus emphasize that they can affect the environmental situation. This feeling of efficacy with regard to the environment has been termed perceived consumer effectiveness (PCE), and is defined as a person's belief that (s)he as an individual consumer can have a positive effect on the environment by altering her/his personal behavior (Do Paço et al., 2013; Roberts, 1996; Webster Jr, 1975). PCE is an important differentiator between those who do and do not display pro-environmental behaviors (Roberts, 1996). An increase in PCE should increase a consumer's feelings of responsibility for the environment and their willingness to make sacrifices for its benefit. The second hypothesis of this study states that:

\section{$\mathrm{H}_{2}$ : Higher perceived consumer effectiveness (PCE) leads to higher levels of consumer environmental stewardship (CENS).}

Finally, it is important to examine the relationship between CENS and proenvironmental behavior. Previous research has shown that pro-environmental behaviors entail multiple dimensions that differ with regard to impact and sacrifices needed in terms of money 
or time spent, and thus differ in difficulty to perform (Englis \& Phillips, 2013). Thus, the relationship of CENS with multiple dimensions of pro-environmental behavior is examined within this study. More specifically, this paper explores conservation behaviors (related to the reduced use of energy, water and other resources), purchasing behaviors (related to the purchase of green products), recycling efforts (for four different materials), environmental activism (e.g., in voting and support for environmental pressure groups) and information seeking related to environmental issues (Bohlen, Schlegelmilch, \& Diamantopoulos, 1993; Minton \& Rose, 1997; Staats, Harland, \& Wilke, 2004). If a consumer displays a high level of CENS (s)he feels more responsible for the environment and has a higher willingness to balance personal interests with the interests of the environment and its beneficiaries. Previous research has shown that a sense of stewardship can lead people to make personal sacrifices for the benefit of others (Wade-Benzoni, Hernandez, Medvec, \& Messick, 2008). Additionally, previous research has shown that consumers with higher levels of responsibility for the environment display more pro-environmental behaviors (Wells, Ponting, \& Peattie, 2011). Therefore, it is a premise of this paper that higher levels of CENS will lead to higher levels of pro-environmental behavior, and, thus the third hypothesis is:

\section{$\mathrm{H}_{3}$ : Higher levels of Consumer environmental stewardship (CENS) lead to higher levels of consumers' pro-environmental behavior.}

Recent research on stewardship behaviors emphasizes their normative basis (Hernandez, 2012). Driven by an underlying role modeling mechanism, people use information about what previous generations did for them to establish a norm for what they will do for the next generation. If the previous generation was generous to them, people are more generous towards the future generation (Wade-Benzoni, 2002). Similarly, consumers use others' behavior as a reference point to decide whether to act in pro-environmental ways (Cialdini, Reno, \& Kallgren, 1990; Goldstein, Cialdini, \& Griskevicius, 2008; Thøgersen, 
2006). Recognizing the importance of norms within this context, the authors take into account perceived descriptive norms illustrative of consumers' beliefs about what most others actually do (the current generation) or did (the previous generation) with regard to the environment (Lapinski \& Rimal, 2005). Controlling for these norms allows the additional influence of their focus variables, AFG and PCE, on CENS to be accounted for. The following study (1) tests the underpinning conceptual model (H1 to H3) regarding the impact of AFG and PCE on CENS, and the impact of CENS on pro-environmental behaviors.

\section{Study 1}

\section{Research Setting}

This paper takes an intergenerational view on environmental stewardship. As such, the target population is defined within a specific age range to limit external influences on the examination of causes and consequences of CENS (e.g., life stage could be influential). Given the forward looking nature of this study, it is most interesting to focus on consumers whose behavior will affect the environment for a long time to come and whose consumption patterns are not so deeply rooted that they are hard to influence. Thus, the study focuses on young adults born after the 1980s. This segment is characterized by having recently transitioned into 'young' parents, being at the start of their career and having increasing budgets for consumption.

Pre-test

As CENS is a new concept introduced in this paper there are currently no scales for its measurement. Thus, the first step was to develop a specific scale to measure CENS. The stepwise procedure as recommended by Netemeyer, Bearden and Sharma (2003) was adopted including scale testing by use of both exploratory and confirmatory factor analysis on two 
different samples. The initial generation of scale items was based on the literature review and definition of CENS as developed in this paper. In addition, previous scales used to measure the stewardship construct in different contexts and with different reference points were examined (e.g., Barbuto \& Wheeler, 2006; de Ruyter, de Jong, \& Wetzels, 2009; Groesbeck, 2001; Hernandez, 2007). Initially, fifteen items were generated. The items reflected the core characteristics of CENS in terms of felt obligation, accountability, balance and sacrifice. These items were scrutinized by two researchers experienced in the field but unfamiliar with the research at hand. As a result four items were deleted due to lack of content validity.

Two studies were undertaken to empirically assess the factor structure, reliability and validity or the CENS scale. In the first study, the scale's dimensionality was assessed through principal axis factoring (SPSS 21) on data from a sample of 213 undergraduate students. The initial solution indicated a one-factor solution, accounting for $59.64 \%$ of variance extracted. One more item was deleted because of lower factor loading (.60) and lack of fit with other scale items (removing the item does not affect the breadth of the scale). The revised 10-item scale was, as expected, best represented by a one-factor solution, accounting for $61.84 \%$ of the variance with good reliability (Cronbach's Alpha = .93).

In the second study, the construct validity of the newly developed scale was assessed by use of a confirmatory factor analysis (CFA). The 10-item scale was administered to a new sample ( $\mathrm{N}=225$ undergraduate students) in combination with two constructs previously used to explain pro-environmental consumer behaviors: 1) PCE (4-item scale, adapted from Roberts, 1996); and 2) Environmental Concern (EC) (4-item scale, adapted from Kim and Choi, (2005)). The EC scale is a short version of the New Environmental Paradigm scale (Dunlap \& Van Liere, 1978; Dunlap, Van Liere, Mertig, \& Jones, 2000). The measurement properties of the focal constructs were assessed by conducting a CFA in LISREL 8.80 (Jöreskog \& Sörbom, 2006). The analysis reveals an adequate fit to the data: $(\chi 2(132)=$ 
291.730, $\mathrm{p}<.001)$, CFI $=.97, \mathrm{NNFI}=.97, \mathrm{RMSEA}=.078$, and SRMR $=.060)$. Convergent validity was supported as the CRs exceed the recommended cut-off value of .7 and the AVEs exceed the recommended cut-off value of .5 (environmental stewardship [CR = .91; AVE = $.51]$, PCE $[\mathrm{CR}=.79 ; \mathrm{AVE}=.50], \mathrm{EC}[\mathrm{CR}=.80 ; \mathrm{AVE}=.50])($ Fornell \& Larcker, 1981). Further, environmental stewardship correlated significantly with both PCE $(r=.70, p<.01)$, and EC $(r=.66, p<.01)$, while PCE and EC also correlated significantly $(r=.56, p<.01)$. Discriminant validity was supported as the square root of the AVE of all three latent variables exceeded the (attenuated) correlation between any of them. The 10 items of the final CENS scale can be found at the top of Table 1.

\section{(Insert Table 1 about here)}

\section{Sample and Procedure}

A survey methodology was adopted to empirically test hypotheses H1-H3 while controlling for the influence of descriptive norms. For this study a sample of 589 undergraduate students was used since they are young adults born after the 1980s. The students participated in a lab session for partial course credit. 344 participants were women (58\%), and the average age of participants was $22.07(\mathrm{SD}=2.28)$. In the lab session respondents were asked to complete an online questionnaire. Confidentially and anonymity were assured. The questionnaire consisted of measures for AFG, PCE, CENS, a battery of items to measure pro-environmental behaviors, norms among the current generation (NCG), norms among the previous generation (NPG), and some demographics. 


\section{Measures}

CENS was measured by use of the 10-item scale that was developed in the pre-test. To measure AFG a 4-item scale was adapted from Wade-Benzoni (2008). PCE was measured by use of the same 4-item scale that was also used in the pre-test. For CENS, AFG and PCE respondents indicated the extent of their agreement to items on a 7-point scale (from $1=$ "strongly disagree" to 7 = "strongly agree"). NCG and NPG were measured by use of two 4item scales based on a scale for measuring descriptive normative beliefs about energy conservation (Nolan, Schultz, Cialdini, Goldstein, \& Griskevicius, 2008). The scale was adapted to represent multiple pro-environmental behaviors. For the NCG items respondents rated the behaviors of residents currently living in their home region. For the NPG items respondents rated the behaviors of a previous generation of residents who lived in their home region a few decades ago. Responses to the questions regarding NCG and NPG were both based on a 7-point scale (ranging from 1 = "never" to 7 = "almost always"). The items for the CENS, AFG, PCE, NCG and NPG scales can be found in Table 1.

Finally, consumers’ pro-environmental behaviors were assessed by use of a battery of items representing the different dimensions of relevant behaviors identified in the literature review. To assess conservation behaviors ten items were used from a scale by Staats, Harland, and Wilke (2004). These items were chosen on the basis of their applicability to the population under study. Pro-environmental purchasing and recycling behaviors and environmental activism were assessed by use of scales developed by Bohlen, Schlegelmilch, and Diamantopoulos (1993). The scale for environmental activism was based on their political action scale and was slightly adapted to fit the context of this study. Three items were used to measure respondents' information seeking behavior related to environmental issues (Minton \& Rose, 1997). For all behavioral items, a 7-point scale was used (ranging from 1 = "never" to 7 = "always"). 
Consumers are rather inconsistent in their pro-environmental behaviors, in the sense that one person might recycle a lot, but conserves little energy, while another consumer acts the other way around (Steg \& Vlek, 2009). This is most likely due to variations in consumers' abilities, opportunities and motivation to perform different environmental behaviors (Thøgersen \& Ölander, 2002). Different consumers are thus likely to take different actions whilst striving to reach the same goal of environmental protection. On the basis of this observation it is more appropriate to operationalize pro-environmental behavior as a formative rather than a reflective construct (Thøgersen \& Ölander, 2002). Accordingly, proenvironmental behavior was treated as a formative construct that encompasses the 28 items from the five scales. The items on pro-environmental behavior can be found in Table 2.

\section{(Insert Table 2 about here)}

Smart PLS 2.0 (Ringle, Wende, \& Will, 2005) was employed in the assessment of the measurement properties of CENS, AFG, PCE, NCG, and NPG. Since the validity and reliability of formative constructs cannot be assessed by conventional statistical techniques (Cohen, Cohen, Teresi, Marchi, \& Velez, 1990), the construct for pro-environmental behavior was excluded from this analysis. The reliability of the used constructs was evaluated by means of composite reliability (CR) and average variance extracted (AVE) (Chin, 1998; Fornell \& Larcker, 1981). For all measures the CR exceeds the recommended cut-off value of .7 and AVE exceeds the recommended cut-off value of .5 (CENS [CR = .94; AVE = .60], $\mathrm{AFG}[\mathrm{CR}=.85 ; \mathrm{AVE}=.59], \mathrm{PCE}[\mathrm{CR}=.87 ; \mathrm{AVE}=.62]$, NCG $[\mathrm{CR}=.87 ; \mathrm{AVE}=.64]$, NPG [CR = .88; AVE = .65] (Fornell \& Larcker, 1981). Furthermore, convergent validity was assessed by inspecting if the manifest variables loaded adequately in magnitude on the hypothesized latent variables (Anderson \& Gerbing, 1988), all but two manifest variables 
exhibited standardized loadings above .7 (Hulland, 1999). One item of the CENS construct and one item of the AFG construct showed loadings of .68, which are close to .7. Both items were retained as both constructs showed good levels of reliability and both items were theoretically important. A detailed overview of item loadings can be found in Table 1. Finally, discriminant validity was assessed by comparing the square root of the AVE with the (attenuated) correlation between the latent variables of CENS, PCE, AFG, NCG, and NPG (Fornell \& Larcker, 1981). The square root of the AVE of the latent variables exceeded the (attenuated) correlation between all latent variable pairs (Table 3). Additionally, crossloadings were scrutinized revealing that no manifest variable loaded higher on another construct than its associated construct. In summary, these findings indicate discriminant validity.

\section{(Insert Table 3 about here)}

\section{Hypotheses Testing}

A partial least squares (PLS) approach was applied to test the hypotheses in their structural model (using a bootstrapping procedure with 200 re-samples) since it allows for latent constructs to be measured formatively (Chin, 1998). This is essential since proenvironmental behavior was operationalized as a formative construct. Model fit was assessed by examining the $\mathrm{R}^{2}$ values of the endogenous constructs, which were .34 for CENS and .57 for pro-environmental behavior. Both $\mathrm{R}^{2}$ values can be categorized as large effect sizes (Cohen, 1988). Furthermore, a GoF value of .53 was obtained, which can be classified as a large effect size (Wetzels, Odekerken-Schröder, \& van Oppen, 2009).

The results confirmed all hypotheses tested. Both, AFG $(\beta=.19, p<.05)$ and PCE $(\beta$ $=.48, p<.01$ ) have a significant positive effect on CENS, supporting hypotheses 1 and 2 . 
That is, higher levels of AFG and higher levels of PCE lead to higher levels of CENS. With regard to the control variables, neither $\mathrm{NCG}(\beta=.12$, n.s. $)$ nor $\mathrm{NPG}(\beta=.08$, n.s. $)$ have a significant influence on CENS. Supporting H3, CENS did have a significant effect on proenvironmental behavior $(\beta=.76, p<.01)$. That is, higher levels of CENS lead to more proenvironmental behaviors.

Tests of a rival model (in which direct effects of antecedents and control variables on pro-environmental behaviors were included) showed similar levels of fit with an $\mathrm{R}^{2}=.34$ for CENS and $\mathrm{R}^{2}=.58$ for pro-environmental behavior $\left(\Delta \mathrm{R}^{2}=.00\right.$ for CENS and $\Delta \mathrm{R}^{2}=.01$ for pro-environmental behavior). The inclusion of direct effects from the antecedents and control variables on pro-environmental behavior did not result in any additional significant effects, nor did it affect the results for hypotheses 1-3, indicating that the results are robust. This model was further used to test for mediation by use of a Sobel-test (Zhao, Lynch Jr, \& Chen, 2010). The indirect effects of AFG $(z=2.19 ; p<.05)$, and PCE $(z=3.86 ; p<.01)$ through CENS on pro-environmental behavior were significant. Since the direct effects of AFG and PCE on pro-environmental behavior were not significant the results can be classified as indirect-only mediation (Zhao et al., 2010). Results are summarized in Figure 1.

\section{(Insert Figure 1 about here)}

The next step in the analysis was to explore in further detail the effects of CENS on pro-environmental behaviors that require different amounts of effort. Simple linear regression was applied to examine the effects of CENS on each pro-environmental behavior. The results are presented in Table 2. In line with the findings of the PLS estimates, CENS has a significant positive effect on each specific pro-environmental behavior. In the conservation and recycling dimensions, effects are on average relatively weak. The exception is refusing 
plastic bags $(\beta=.463, p<.01)$. Stronger effects are observed in reported purchasing, information seeking and environmental activism behaviors. The strongest effects are observed for trying to discover environmental effects of products prior to purchase $(\beta=.572, p<.01)$, paying attention to advertisements about pro-environmental products $(\beta=.562, p<.01)$, and considering green issues in voting behaviors $(\beta=.551, p<.01)$.

\section{Exploring Potential Interaction Effects between Affinity with Future Generations (AFG) and Perceived Consumer Effectiveness (PCE)}

Study One confirms that AFG and PCE are two important predictors of CENS. Extant research in the domain of pro-environmental behavior has paid limited attention to AFG (Wade-Benzoni, 2008), while ample studies on PCE predominantly focus on consumers' general beliefs that they can personally influence the state of the environment. Many of those studies test new scales or different sets of contextual antecedents when examining the direct effects of PCE on pro-environmental behavior (Cleveland, Kalamas, \& Laroche, 2005; Cleveland et al., 2012; Kim \& Choi, 2005; Kinnear, Taylor, \& Ahmed, 1974; Roberts, 1996). This study goes a step further by exploring the interaction between AFG and PCE.

Research on social dilemmas has shown that both self-efficacy and public good remedies (measures that increase the relevance of cooperative outcomes) can stimulate cooperative actions (Kerr, 1996). AFG is a stewardship antecedent that fits the characteristics of a public good remedy, while PCE is a measure of efficacy with regard to the environment. Public good remedies and efficacy are expected to interact such that public good remedies are less influential when people believe that they cannot personally impact the collective outcomes and more effective when people believe that they can have an impact on the collective outcomes (Kerr, 1996). If marketing communications increase the relevance of taking responsible action through an increase in AFG, while feelings of PCE are high, 
consumers have both a reason for and the ability to act pro-environmentally, making it more likely that they perform pro-environmental behavior. It is proposed within this study that a stimulus that increases AFG under conditions of high PCE will result in the highest levels of

CENS. However, if marketing communications stimulate AFG, but the consumer does not believe that they can have any positive influence on collective outcomes then there is no reason to cooperate.

Importantly, increasing the relevance of responsible behavior can result in more responsible behavior under high efficacy, but can backfire and result in more damaging behavior under low efficacy (Rippetoe \& Rogers, 1987; White, MacDonnell, \& Ellard, 2012; Witte, 1992; Wolburg, 2001). Low efficacy can cause people to reject marketing messages and entice them to do the opposite of what is asked. The message can create a feeling of hopelessness and fatalism that causes people to increase damaging behavior. This study therefore poses that an AFG stimulus can result in boomerang effects under low levels of PCE.

H4: There is an interaction between AFG and PCE on CENS, where higher AFG leads to higher levels of CENS when PCE is high, but where higher AFG leads to lower levels of CENS when PCE is low.

To explore the interaction between AFG and PCE, three experimental studies were designed in which respondents' AFG and PCE were both stimulated. This allowed the authors to demonstrate the impact of AFG and PCE and any interaction on CENS. In these experiments techniques were devised to stimulate both AFG and PCE, thus demonstrating how these antecedents can be manipulated through marketing communications. Study 2 served as a first test of the interaction hypothesis and was conducted within a student population. Additionally, a third study was conducted to test the robustness of the findings of Study 2 and assess external validity by testing the hypothesis in a sample drawn from the general public, in which a proportion of people have children. Finally, a fourth study was 
conducted to test the hypotheses with different manipulations that reflect mainstream marketing stimuli likely to be encountered by consumers (e.g., in store advertising and product labeling).

\section{Study 2}

\section{Stimuli and Pre-test}

People's AFG can be stimulated by making them think of their own progeny (WadeBenzoni, 1999; Wade-Benzoni \& Tost, 2009). By thinking of their own children it becomes easier to envision future generations, reducing the social distance that would prevent them from acting on the future generation's behalf. A stimulus was designed to help respondents think of their own progeny in the form of a story writing task about having (grand)children of their own (high-AFG condition). Since this experiment utilizes a student sample of young adults born after the 1980s who mostly do not have children, a text was added that asked respondents in the high-AFG condition to imagine how it would be to have (grand)children of their own and how they would see their relationship with them. In addition, a neutral stimulus was designed to ensure that people in the neutral-AFG condition faced similar circumstances to people in the high-AFG condition other than the intended differences between stimuli. This neutral stimulus involved a story writing task about respondents' favorite brand and their relationship with it. The AFG stimuli used are presented in Appendix A.

The two AFG stimuli were pre-tested prior to the actual experiment. Twenty six people without children were randomly assigned to either the neutral- or high-AFG condition (14 respondents in the neutral-AFG condition and 12 in the high-AFG condition). After the story writing task they were asked to answer questions about their AFG and PCE. The same scales were used as in study 1, except "that will be living in my home region" was removed from each AFG item in this pre-test (Cronbach’s alpha: AFG $=.92$, PCE $=.89$ ). Respondents 
in the high-AFG condition showed significantly higher levels of AFG than respondents in the neutral-AFG condition ( $\mu_{\text {hafg }}=5.44$ vs. $\mu_{\text {nafg }}=3.71, p<.01$ ), while there were no significant differences with regard to PCE ( $\mu_{\text {hafg }}=6.13$ vs. $\mu_{\text {nafg }}=5.88$, n.s. $)$ demonstrating that the manipulation worked well.

Additionally, two stimuli were developed to influence respondents' PCE levels. A newspaper article was utilized, since previous research shows that media coverage has a large impact on public perceptions with regard to PCE (Roberts, 1996). Furthermore, consumers often see themselves as powerless compared to large industrial companies (Pieters, Bijmolt, van Raaij, \& de Kruijk, 1998). This information was used to write two articles: the first was aimed at lowering respondents PCE by arguing that consumers can have relatively little effect compared to industry (low-PCE condition); while the second was aimed at raising respondent's PCE by arguing that consumers can have a relatively big effect compared to industry (high-PCE condition). The PCE stimuli used can be found in Appendix B.

The PCE stimuli were pre-tested on a sample of 80 people who were randomly assigned to one of the two conditions (low-PCE vs. high-PCE). 44 respondents were allocated to the low-PCE condition and 36 to the high-PCE condition. They were asked to read a short newspaper article and think of a headline to go with the article. Afterwards, they completed the PCE scale (Cronbach's alpha $=.87$ ), AFG scale (Cronbach's alpha $=.80$ ) and rated the credibility of the article. Credibility of the newspaper articles was assessed by respondents indicating to what extent they agreed that the newspaper article they read was credible, believable and realistic on a 7-point scale (Cronbach’s alpha $=.94)$. Furthermore, no differences were found between the groups with regard to age, gender and children. As expected respondents in the high-PCE condition showed significantly higher levels of PCE than people in the low-PCE condition $\left(\mu_{\mathrm{hpce}}=6.09\right.$ vs. $\left.\mu_{\mathrm{lpce}}=4.73, p<.01\right)$, but there were no 
significant differences for AFG ( $\mu_{\text {hpce }}=5.25$ vs. $\mu_{\text {lpce }}=5.16$, n.s. $)$ or credibility $\left(\mu_{\text {hpce }}=5.08\right.$ vs. $\mu_{\text {lpce }}=5.30$, n.s.).

\section{Experimental Setup}

For this experiment a 2 (AFG: neutral, high) $\times 2$ (PCE: low, high) between-subjects design was used. Data were collected from 156 undergraduate students who participated in a lab session. Four participants were excluded from the study as they had not fully completed the scales and a further 5 participants did not complete one or more of the tasks appropriately (e.g., leaving the task blank). Of the remaining 147 respondents in the sample, 49.7\% (73) were female participants, the mean age was 19.80 years $(\mathrm{SD}=1.12$, range $=18-27)$ and no participants had children. Confidentiality was assured. Respondents were randomly assigned to one of the 4 conditions (36 in the neutral AFG-low PCE condition, 40 in the neutral AFGhigh PCE condition, 35 in the high AFG-low PCE condition and 36 in the high AFG-high PCE condition).

Respondents took at least 5 minutes to write their story (AFG stimulus) and at least 5 minutes to read the newspaper article and come up with their headline (PCE stimulus). When finished, respondents completed a questionnaire comprised of the CENS measure (Cronbach’s alpha=.89) and a behavioral measure assessing whether people would act on their environmental stewardship and forgo personal benefits for the collective good. The behavioral measure consisted of a lottery assignment where participants were asked to imagine they won a lottery and were invited to indicate the percentage of lottery winnings, if any, they would be prepared to donate to support charitable initiatives to protect the environment. Participants then completed the AFG (Cronbach’s alpha $=.92)$, PCE (Cronbach’s alpha $=.82$ ) and credibility (Cronbach's alpha $=.85$ ) scales described previously. Following a short filler task, participants then answered questions on demographics. Finally, 
feelings of reactance, measured as a co-variate, were assessed by use of three items from the "resisting influence from others" dimension of the Hong Psychological Reactance Scale (Cronbach's alpha $=.66)($ Hong \& Faedda, 1996).

The manipulation check results were in line with the pre-tests. Respondents in the high-AFG condition showed significantly higher levels of AFG than the neutral-AFG group $\left(\mu_{\text {hafg }}=4.57\right.$ vs. $\left.\mu_{\text {nafg }}=2.98, p<.01\right)$. Respondents in the high-PCE condition showed significantly higher levels of PCE than the low-PCE condition $\left(\mu_{\text {hpce }}=5.32\right.$ vs. $\mu_{\text {lpce }}=4.44, p$ $<.01)$, whilst both groups found the article to be a credible source of information $\left(\mu_{\mathrm{lpce}}=4.50\right.$, $\mu_{\text {hpce }}=4.73$, n.s.).

\section{Hypothesis Testing}

A two-way ANOVA was conducted to assess the effects of the AFG and PCE stimuli on CENS. Contrary to hypothesis 1 , the results show no significant effect of AFG $(F(1,143)$ $=.76$, n.s.), but in line with hypothesis 2 the results do reveal a significant positive effect of PCE $\left(F(1,143)=8.89, p<0.01, \eta^{2}=0.059\right)$. However, coefficients for the individual antecedents should be interpreted with caution, since significant interaction effect was found between AFG and PCE on CENS $\left(F(1,143)=9.83, p<0.01, \eta^{2}=0.064\right)$, which provides support for hypothesis 4. This interaction effect is represented in figure 2.

\section{(Insert Figure 2 about here)}

Planned contrasts tests indicate that there is a significant difference between the high AFG-high PCE condition and the high AFG-low PCE condition $\left(\mu_{\text {hafg-hpce }}=4.40\right.$ vs. $\mu_{\text {hafg-lpce }}$ $=3.52, p<.01)$. The high AFG-high PCE condition is also significantly different from the other two conditions ( $\mu_{\text {hafg-hpce }}=4.40$ vs. $\mu_{\text {nafg-hpce }}=3.82, p<.01 ; \mu_{\text {hafg-hpce }}=4.40$ vs. $\mu_{\text {nafg-lpce }}$ 
$=3.84, p<.01)$. No other significant differences were found. It is interesting that overall the group had a low mean score on CENS $\left(\mu_{2}=3.90(.915)\right)$, which aids in emphasizing the positive impact of the high AFG-high PCE condition on CENS. These results provide good support for H4, demonstrating that stimulation of a consumer's AFG can increase levels of CENS when paired with higher PCE. Respondents in the condition in which high AFG coincided with low levels of PCE showed the lowest levels of CENS. This is a first indication that an increase in AFG could decrease a consumer's level of CENS if they feel that they have little individual influence on environmental change.

To test the robustness of these findings the analyses were replicated while controlling for gender and feelings of reactance. Gender was significant as a co-variate (women showed higher levels of CENS than men), consistent with previous literature (Vicente-Molina, Fernández-Sáinz, \& Izagirre-Olaizola, 2013). Reactance was not significant as a covariate $\left(F_{\text {gender }}(1,141)=5.13, p<0.05, \eta^{2}=.035 ; F_{\text {reactance }}(1,141)=3.74\right.$, n.s. $)$. Importantly, when controlling for these covariates the significant effects of the focal variables did not change.

As a final step the authors assessed the relationship between CENS and consumers’ intentions to act in a pro-environmental way with regard to the lottery draw winnings by use of simple linear regression analysis. In line with H3, CENS has a significant and positive influence on the amounts of money consumers are willing to give to charity $(F=19.337, p<$ 0.01 , adj. $\left.\mathrm{R}^{2}=.11, \beta=.343, p<0.01\right)$. Higher levels of CENS can help consumers overcome their self-interest and act in pro-environmental ways.

\section{Study 3}

Whilst the samples used previously were drawn from student groups that were representative of the target population of young adults born after the 1980s, the authors wanted to test the external validity of their findings by including people from the wider public 
within this generation who were also more likely to have children. An additional experiment was conducted to test the robustness of the findings from study 2 that the stimulation of AFG has a different effect on CENS depending on the level of PCE. In this third study the same method as for study 2 was utilized but with a sample drawn from the general public.

\section{Stimuli and Pre-tests}

For study 3 the same stimuli were used to manipulate PCE and AFG. Since this study approached the wider public with a mix of people with and without children, another pre-test of the AFG stimulus was conducted among this specific audience to make sure that the reference to people's children had the same effect in this population. In this pre-test 58 people (46.5\% of whom had one or more children) participated in an online questionnaire for a small monetary compensation. Participants were randomly assigned to one of the two conditions, wrote a short story and afterwards answered questions on AFG (Cronbach’s alpha = .93) and PCE (Cronbach's alpha $=.89$ ). Thirty three respondents were assigned to the neutral-AFG condition and 25 to the high-AFG condition (groups did not significantly differ with regard to having children). The results confirmed that people in the high-AFG condition showed significantly higher levels of AFG than people in the neutral-AFG group ( $\mu_{\text {hafg }}=5.19 \mathrm{vs.} \mu_{\text {nafg }}$ $=3.73, p<.01)$, while there were no significant differences on PCE $\left(\mu_{\text {hafg }}=5.92\right.$ vs. $\mu_{\text {nafg }}=$ 5.85, n.s.).

\section{Experimental Setup}

A 2 (AFG: neutral, high) $\times 2$ (PCE: low, high) between-subjects design was used. A market research company was commissioned to run the experiment. The company recruited 139 respondents between the ages of 18 and 30 from their national panel through an online personal link. Confidentiality was assured. The market research company applied their 
standard quality validation procedures in the process of recruiting participants. Nine respondents were excluded from the analyses because they did not follow the instructions with regard to the story writing assignment. The mean age of participants was 24.9 years (SD = 3.60), $58 \%$ (75) of participants were women, $32 \%$ (42) had one or more children.

Respondents were randomly assigned to one of 4 conditions (34 in the neutral AFG-low PCE condition, 33 in the neutral AFG-high PCE condition, 32 in the high AFG-low PCE condition and 31 in the high AFG-high PCE condition). Respondents were first exposed to the AFG stimulus and asked to take at least 5 minutes to write a short story. Thereafter, they were asked to read a newspaper article containing the PCE stimulus and produce their own headline. Following the two tasks, they completed the measure for CENS (Cronbach's alpha = .92) and the same behavioral measure (lottery assignment) as used in study 2. As a final part of the online questionnaire respondents were asked about their AFG (Cronbach's alpha $=.92$ ), PCE (Cronbach's alpha = .78), demographics and feelings of reactance (Cronbach's alpha = .56) (Hong \& Faedda, 1996), as described for Study 2. The manipulation check results were in line with the pre-tests. Respondents in the high-AFG condition showed significantly higher levels of AFG than the neutral-AFG group ( $\mu_{\text {hafg }}=4.85$ vs. $\mu_{\text {nafg }}=4.35, p<.05$ ), while respondents in the high-PCE condition showed significantly higher levels of PCE than the low-PCE condition $\left(\mu_{\mathrm{hpce}}=5.00\right.$ vs. $\left.\mu_{\mathrm{lpce}}=4.31, p<.01\right)$.

\section{Hypothesis Testing}

Two-way ANOVA analyses were utilized to estimate the effects of the stimuli on CENS. The results were in close agreement with those found in study 2. Contrary to hypothesis 1 there was no significant main effect of $\operatorname{AFG}(F(1,126)=1.52$, n.s. $)$, but in line with hypothesis 2 there was a significant main effect of PCE $\left(F(1,126)=5.91, p<.05, \eta^{2}=\right.$ .05). In support of H4, the results show a significant interaction effect between AFG and PCE 
on CENS $\left(F(1,126)=8.34, p<.01, \eta^{2}=.06\right)$. A visual representation of the interaction effect is presented in Figure 3.

\section{(Insert Figure 3 about here)}

An examination of the contrasts revealed that, as in study 2, the difference between the high AFG-high PCE condition and the high AFG-low PCE condition was significant ( $\mu_{\text {hafg-hpce }}$ $=5.00$ vs. $\left.\mu_{\text {hafg-lpce }}=4.15, p<.01\right)$. A significant difference was found between the other two conditions and the high-AFG-low-PCE condition ( $\mu_{\text {nafg-hpce }}=4.73$ vs. $\mu_{\text {hafg-lpce }}=4.15, p<.05$; $\mu_{\text {nafg-lpce }}=4.80$ vs. $\mu_{\text {hafg-lpce }}=4.15, p<.01$ ). No other significant differences were found, but the mean level of CENS was highest for the high AFG-high-PCE condition. It is worth noting that in this sample the overall mean CENS score is higher than those for the sample in study 2 ( $\mu_{3}=4.65$ (.953) versus $\mu_{2}=3.90$ (.915)). This aids in emphasizing the negative impact of the high AFG-low PCE interaction on lowering CENS. These results provide further support for hypothesis 4 by showing that the stimulation of consumer's AFG is only positively impactful on CENS under conditions of higher PCE. It can actually decrease levels of CENS if consumers feel that they have little personal influence on the environment. These results confirm the proposition that AFG stimuli can backfire when consumers experience low levels of PCE.

To test the robustness of the results the analyses was replicated whilst controlling for gender and feelings of reactance, as in study 2, and additionally, for being a parent. None of the included control variables had a significant effect and the significant effects of the focal variables did not change $\left(F_{\text {gender }}(1,123)=1.34\right.$, n.s.; $F_{\text {reactance }}(1,123)=3.05$, n.s.; $F_{\text {parent }}(1$, 123) $=2.12$, n.s.). 
Finally, the authors assessed the relationship between CENS and consumers' intention to exert pro-environmental behavior with regard to the lottery draw winnings by use of simple linear regression analysis. The results support hypothesis 3 and are in agreement with study 2. CENS has a significant positive influence on the amounts of money consumers are willing to give to charity $\left(F=20.97, p<.01\right.$, adj. $\left.\mathrm{R}^{2}=.13, \beta=.375, p<.01\right)$. This provides further evidence that higher levels of CENS can help consumers to overcome their self-interest and act in pro-environmental ways.

\section{Study 4}

In Study 4 the hypotheses were tested with manipulations that reflect mainstream marketing stimuli likely to be encountered by consumers. An advert (to manipulate AFG) and produce label information (to manipulate PCE) were developed for an ecologically produced wooden chair.

\section{Stimuli and Manipulation Checks}

The AFG stimulus was based on an existing advert for an ecologically produced wooden chair. The brand name was replaced with a fictitious name. The neutral AFG advert presented a person sitting in the chair with the slogan "relaxing moments spent comfortably". The high AFG advert presented a picture of the same person and besides them a child sitting in another chair, with the slogan "relaxing moments to share and pass on”. The PCE stimulus was based on the label information provided with the chair. The low PCE label presented ecological information about the chair using terminology emphasizing the producer's effectiveness with the end slogan "leave it to us so that you can sit comfortably". The high PCE label presented the same ecological information using terminology emphasizing the individual's effectiveness with the end slogan “you can make a difference”. 
The manipulation checks confirmed that people in the high-AFG condition showed significantly higher levels of AFG than people in the neutral-AFG group ( $\mu_{\text {hafg }}=5.28 \mathrm{vs.} \mu_{\text {nafg }}$ $=3.30, p<.01)$, while there were no significant differences on PCE $\left(\mu_{\mathrm{hafg}}=5.00 \mathrm{vs} . \mu_{\mathrm{nafg}}=\right.$ 4.98, n.s.). Respondents in the high-PCE condition showed significantly higher levels of PCE than the low-PCE condition ( $\mu_{\text {hpce }}=5.50$ vs. $\mu_{\text {lpce }}=4.37, p<.01$ ), while there were no significance differences on AFG ( $\mu_{\mathrm{hpce}}=4.42$ vs. $\mu_{\mathrm{lpce}}=4.11$, n.s. $)$.

\section{Experimental Setup}

A 2 (AFG: neutral, high) $\times 2$ (PCE: low, high) between-subjects design was used. The sample was drawn from student groups representative of the target population of young adults born after the 1980s. Both undergraduate and postgraduate students were invited to participate to cover a good spread within the age ranges under study. This also facilitated capturing young adults born after the 1980s who may have children. Data were collected from 154 students between the ages of 18 and 30. Confidentiality was assured. Two respondents were excluded from the analyses as they provided incomplete answers. The mean age of participants ( $\mathrm{N}=152$ ) was 22.79 years ( $\mathrm{SD}=3.87$ ), 58.6\% (89) of participants were women, $30(19.7 \%)$ had one or more children. Respondents were randomly assigned to one of 4 conditions (39 in the neutral AFG-low PCE condition, 40 in the neutral AFG-high PCE condition, 30 in the high AFG-low PCE condition and 43 in the high AFG-high PCE condition). Respondents were asked to imagine that they were in a store to purchase a garden chair, and were then exposed to the AFG advert stimulus and PCE label stimulus (or vice versa as the stimuli order was randomized). Respondents then completed the CENS (Cronbach's alpha $=.96$ ), behavioral intentions items (7-items, measuring willingness to recommend, willingness to patronize the company, price sensitivity; drawn from The Behavioral Intentions Battery, Zeithaml, Berry, \& Parasuraman, 1996; Cronbach’s alpha = 
.89), AFG (3-items, Cronbach's alpha = .95), PCE (3-items, Cronbach's alpha $=.76)$ and demographic items.

Hypothesis Testing

Two-way ANOVA analyses were conducted to estimate the effects of the stimuli on CENS. The results aligned closely with the results for studies 2 and 3. Contrary to hypothesis 1 there was no significant main effect of $\operatorname{AFG}(F(1,148)=.98$, n.s. $)$. In agreement with hypothesis 2 there was a significant main effect of $\operatorname{PCE}\left(F(1,148)=7.97, p<.01, \eta^{2}=.051\right)$. There was also a significant interaction effect between AFG and PCE on CENS $(F(1,148)=$ 9.33, $p<.01, \eta^{2}=.059$ ), as per hypothesis 4 (see figure 4 for the interaction effect).

\section{(Insert Figure 4 about here)}

The planned contrasts indicated, as in studies 2 and 3, a significant difference between the high AFG-high PCE condition and the high AFG-low PCE condition ( $\mu_{\text {hafg-hpce }}=5.05$ vs. $\mu_{\text {hafg-lpce }}=3.86, p<.01$ ). There were also significant differences between the other two conditions and the high-AFG-high-PCE condition ( $\mu_{\text {hafg-hpce }}=5.05$ vs. $\mu_{\text {nafg-lpce }}=4.28, p<.01$; $\mu_{\text {hafg-hpce }}=5.05$ vs $\mu_{\text {nafg-hpce }}=4.23, p<.01$ ). No other significant differences were found. To test the robustness of the results the analyses was replicated whilst controlling for gender and for being a parent. None of the control variables had a significant effect. Confirming studies 2 and 3, the results of study 4 imply that AFG stimuli can backfire when consumers experience low levels of PCE. That is, stimulation of consumer's AFG is positively impactful on CENS under conditions of higher PCE, but it can actually decrease levels of CENS under conditions of low PCE.

Finally, CENS had a small but significant positive influence on participants’ behavioral intentions in terms of their willingness to engage with environmentally friendly 
products (willingness to recommend, patronize the company and price sensitivity) ( $F=8.79$, $\mathrm{p}$ $<.01$, adj. $\left.\mathrm{R}^{2}=.049, \beta=.235, \mathrm{p}<.01\right)$.

\section{Discussion}

Despite heavy investment in information and incentive campaigns, contemporary consumers do not adopt environmentally-friendly behaviors at a level necessary for future sustainability. Information-only campaigns are limited in effectiveness especially in entrenched behaviors (Whitmarsh \& O'Neill, 2010), while incentive campaigns are costly and stimulate a focus on extrinsic motivations (Prothero et al., 2011). What is needed is a fundamental shift in perceptions. This paper set out to establish how consumers could be encouraged to adopt pro-environmental behaviors more effectively than current attempts through understanding perceived responsibility. The first contribution is to advance the understanding of consumer responsibility for pro-environmental behaviors through the development of the concept of consumer environmental stewardship (CENS). From a theoretical perspective the conceptualization of CENS presented within this paper extends the notion of stewardship beyond its contemporary organizational boundaries (de Ruyter et al., 2009; Wasserman, 2006). The evidence offered by this paper supports Hernandez's (2012) claim that stewardship can be applied to a broader set of situations and at an individual consumer level. In particular, to situations where there are no formal contractual relationships to behave in certain ways, which is especially pertinent to the consumer context in this study. Responsibility for the environment as captured in the CENS concept is a broader concept that is not synonymous with obligation (e.g., Stern, 2000), but instead incorporates other facets. That is, in lieu of relationships based on formal contracts, consumers can adopt a stewardship perspective through not only a sense of obligation but also accountability alongside a 
balancing of their needs against the larger entity and making sacrifices (e.g., financial, time, convenience) if necessary.

Furthermore, the authors test the usefulness of CENS as the responsibility mechanism through which consumers can be stimulated to adopt behaviors with long-term collective benefits such as pro-environmental behaviors. The second main contribution of this paper therefore stems from the exploration of the antecedents of CENS and its subsequent impact on pro-environmental behaviors. Previous research on the stewardship concept has mainly focused on laying the theoretical groundwork and identifying potential stewardship antecedents in an organizational context such as identification with a bigger entity, selfefficacy and social norms (Davis et al., 1997; Hernandez, 2008, 2012). Yet, to the best of the authors' knowledge, no studies have operationalized or empirically tested a conceptual model centering on stewardship in a consumer context. This paper contributes to the literature on stewardship and pro-environmental behavior by bringing these research streams together and empirically testing the proposed model. In this process relevant antecedents of CENS were identified by looking at factors that have previously been used in the social marketing context. AFG, which stems from intergenerational dilemma research (Wade-Benzoni, 2008), was used to increase the affective connection and identification with the bigger entity. PCE, which is an important construct in environmental research (Roberts, 1996), was used to increase feelings of efficacy.

Overall, the proposed conceptual framework, built stage wise through each of the studies, enables a better understanding of how to stimulate CENS and, crucially, how to avoid reducing CENS and the concomitant negative behavioral outcomes. The results of study 1 show that AFG and PCE both emerge as strong predictors, and therefore influencers of CENS. This is consistent with research in other areas showing that PCE and AFG are strong predictors of behavior aimed to benefit a bigger entity (e.g., Roberts, 1996; Wade-Benzoni, 
2008). It is these two factors that offer much promise in terms of stimulating CENS if applied appropriately. More specifically, the results of studies 2, 3 and 4 show that increasing AFG has a positive effect under high levels of PCE, but can also have harmful effects under low levels of PCE. This is consistent with research in public health campaigns, which finds that increases in message relevance (e.g., through increased 'threat' or 'fear') can result in more damaging behavior under low levels of efficacy (Rippetoe \& Rogers, 1987; Wolburg, 2001). It has been argued that this happens because people resort to defensive mechanisms, such as denial, to cope with the "hopeless" situation (Krisjanous, Ashill, Eccarius, \& Carruthers, 2013; Witte, 1992).

Furthermore, all four studies show that there is a clear indication that stimulating CENS can foster pro-environmental behaviors. Most importantly, within the framework and throughout the four studies, CENS is shown to be a mediator of the relationships between AFG and PCE on pro-environmental behavior. Additionally, study 1 shows that people with higher levels of CENS more often perform pro-environmental behaviors. This is the case for all tested behavioral dimensions. On average, the effects of CENS on pro-environmental behaviors are weaker for conservation and recycling behaviors, which happen to be the proenvironmental behaviors that are more often performed in general. This might be a result of the large amounts of attention and spending that have been attributed to change policies and facilitate these 'assisted behaviors' over recent years. CENS has a stronger effect on those proenvironmental behaviors that require higher levels of cognitive involvement such as proenvironmental purchase behaviors, environmental activism and information seeking. Previous research has shown that cognitive involvement plays an important role in the promotion of ‘desirable’ (positive) behaviors (Krisjanous et al., 2013). The stimulation of CENS could potentially play a role in this process and foster these pro-environmental behaviors to become more commonplace. 


\section{Managerial and Practitioner Implications}

This research shows that AFG and PCE are important catalysts of CENS and indirectly pro-environmental behaviors, that can be stimulated (at least for a short while) through marketing communications. Studies 2, 3 and 4 show that AFG can be stimulated by making people think of their own children or grandchildren or subsequent (younger) generations. It is promising that the stimulus used also worked for people who did not yet have children (study 2). Whilst a story writing task was used in the first studies to stimulate AFG, the same effect was achieved through a print ad that stimulated people to think of younger generations (study 4). As such AFG could serve as a way "to instill a sense of the future in consumers" that benefits sustainability goals (Urien \& Kilbourne, 2011, p. 84). PCE can be stimulated by highlighting the importance of consumers' decisions to achieve sustainability as was shown in studies 2,3 and 4 . Consumers feel relatively small compared to large corporations and governments, still all consumers together have a major impact. Marketing communications, for example, product labeling information as used in study 4, can be used to highlight this fact and thereby compensate for low levels of PCE.

The findings in studies 2, 3 and 4 are in line with the results of social marketing campaigns. This is especially the case for those looking at larger scale public health issues that strongly indicate that increasing the relevance of responsible behavior to the individual can result in more damaging behaviors under conditions of low efficacy (Witte, 1992; Wolburg, 2001). The approach used in this study demonstrates how current communication approaches could be enhanced. It shows that marketing communications that stimulate AFG can promote CENS if combined with feedback signaling high PCE. AFG as a stimulus is significantly more effective in fostering CENS among people in the context of higher levels of PCE. However, this comes with a warning caveat. A message that stimulates AFG can backfire reducing CENS if levels of PCE are perceived as low by the individual. This finding 
holds several implications for commercial, governmental and non-profit organizations that use (e.g., the WWF uses communications that refer to future generations) or want to use AFG oriented communications to further the environmental cause or promote green products. First, it is better not to use AFG oriented marketing communications to target consumer groups that are known to show lower levels of PCE. Prior research has found lower PCE levels in (i) younger age groups and lower socio-economic groups, (ii) those with less education in environmental issues and higher levels of trust in science and political leaders, and, (iii) on a wider scale, related to cultural differences, those with lower altruistic motivation levels (DEFRA, 2008; Kellstedt, Zahran, \& Vedlitz, 2008; Vicente-Molina et al., 2013). Second, it is best to only use AFG oriented marketing communications in surroundings where they are unlikely to be accompanied by messages that stimulate low levels of PCE (e.g., channels that report news about environmental issues in business). Thus, it might be best to integrate a PCE stimulus in marketing communications that aim to stimulate AFG. The CENS scale that was developed can be used to test the effectiveness of designed communications. Overall, the strong evidence of construct validity across the four studies plus scale parsimony (ten-item construct) present this scale as a very usable tool for researchers and practitioners alike.

\section{Limitations and Future Research Directions}

The findings introduce several opportunities for future research. In terms of conceptual development, establishing the nature and extent of the CENS concept across different cultures would provide important insights into the concept of stewardship as it applies to environmentally-friendly behaviors. For example, within the wider cultural debate about attitudes toward the environment, citizens within horizontal (whether individualistic or collectivistic) cultures tend to have positive attitudes toward the environment. In contrast, citizens within vertical (whether individualistic or collectivistic) cultures tend to have more 
negative environmental attitudes (Cho, Thyroff, Rapert, Park, \& Lee, 2013). Vertical power orientations may be linked to more inward-looking views that create more perceived distance from the environment, the benefits of environmentally friendly actions and other generations. Such cultural distinctions may act as important boundary conditions. Furthermore, this research focuses on a specific generation of young adults born after the 1980s. While this provides advantages with regard to internal validity, it presents a disadvantage with regard to external validity. Future research should assess to what extent the promotion of CENS helps to further pro-environmental behaviors among older generations. Furthermore, there are opportunities for scale development. In particular, assessing the CENS scale's validity among people outside of the generation of young adults born after the 1980s would be beneficial.

Although the stimuli to manipulate AFG and PCE proved effective in the short run it would be interesting to explore their effects on CENS in the long run. It would be especially interesting to examine how repetitive exposure to such stimuli affects the development of CENS. Longitudinal research designs could help to examine these effects. While the stimuli proved to be effective among young adults born after the 1980s, future research should examine if the effect is similar among older audiences. Previous research has shown that older people generally become more altruistic (Mathur, 1996). It has also been argued that older people become more concerned about the legacy they leave as a consequence of increased mortality salience (Fox, Tost, \& Wade-Benzoni, 2010; Grant \& Wade-Benzoni, 2009). These findings hint at a potentially higher effectiveness of the AFG stimuli among older age groups, but future research will have to establish if this is the case. Furthermore, the stimuli focused on children and grandchildren. These are people of the future generations that are very close to those living today and easily identifiable. That is, there is limited social distance (WadeBenzoni, 2008). Additionally, thinking of your children or grandchildren can instill a sense of future while simultaneously increasing message relevance and positive emotions. These 
aspects are argued to increase message acceptance and a willingness to strive for sustainability (Krisjanous et al., 2013; Urien \& Kilbourne, 2011). Future research should identify the effectiveness of using different future others (in terms of distance) as there could be a threshold after which AFG stimuli become ineffective.

Finally, while testing the conceptual model in study 1 the social normative influence, which is argued to be relevant for stewardship stimulation, was controlled for by use of NCG and NPG. Contrary to expectations, consumers' perceptions of NCG and NPG did not have a significant effect on CENS. Previous findings by Wade-Benzoni (2002) showed that descriptive norms that are signaled through role modeling behaviors from both the current and the previous generation can stimulate people to overcome self-interest and serve the benefit of future others. Whilst the difference with her findings may be due to the more immediate role that AFG and PCE have, it cannot be ruled out that this could be a result of the difference in approach. While Wade-Benzoni (2002) used experimental stimuli in which benefits to future others were made very salient, this study used a survey design asking about perceptions of descriptive norms where benefits to others were not explicitly mentioned. Previous research on social norms has shown that such differences can have a large effect on outcomes (Lapinski \& Rimal, 2005). Therefore, future research that contrasts these different approaches could be instigated to provide more conclusive insights about the role of descriptive norms in the stimulation of CENS. Additionally, it might be interesting to examine the role of injunctive norms (Cialdini et al., 1990), especially in older generations with a heightened awareness of their legacy (Fox et al., 2010). 


\section{References}

Anderson, J. C., \& Gerbing, D. W. (1988). Structural equation modeling in practice: A review and recommended two-step approach. Psychological Bulletin, 103, 411-423.

Barbuto, J., John E., \& Wheeler, D. W. (2006). Scale development and construct clarification of servant leadership. Group \& Organization Management, 31, 300-326.

Batson, C. D. (1987). Prosocial motivation: Is it ever truly altruistic? In L. Berkowitz (Ed.), Advances in experimental social psychology, vol. 20. (pp. 65-122). San Diego, CA, US: Academic Press.

Block, P. (1993). Stewardship: Choosing service over self-interest. San Francisco, CA: Berrett-Koehler.

Bohlen, G., Schlegelmilch, B. B., \& Diamantopoulos, A. (1993). Measuring ecological concern: A multi-construct perspective. Journal of Marketing Management, 9, 415430.

Chin, W. W. (1998). The partial least squares approach to structural equation modeling. In G. A. Marcoulides (Ed.), Modern methods for business research (pp. 295-336). Mahwah, NJ: Lawrence Erlbaum Associates.

Cho, Y.-N., Thyroff, A., Rapert, M. I., Park, S.-Y., \& Lee, H. J. (2013). To be or not to be green: Exploring individualism and collectivism as antecedents of environmental behavior. Journal of Business Research, 66, 1052-1059.

Cialdini, R. B., Reno, R. R., \& Kallgren, C. A. (1990). A focus theory of normative conduct: Recycling the concept of norms to reduce littering in public places. Journal of Personality and Social Psychology, 58, 1015-1026.

Cleveland, M., Kalamas, M., \& Laroche, M. (2005). Shades of green: Linking environmental locus of control and pro-environmental behaviors. Journal of Consumer Marketing, 22, 198-212.

Cleveland, M., Kalamas, M., \& Laroche, M. (2012). 'It's not easy being green': Exploring green creeds, green deeds, and internal environmental locus of control. Psychology \& Marketing, 29, 293-305.

Cohen, J. (1988). Statistical power analysis for the behavioral sciences. Hillsdale NJ: Lawrence Erlbaum Associates.

Cohen, P., Cohen, J., Teresi, J., Marchi, M. L., \& Velez, C. N. (1990). Problems in the measurement of latent variables in structural equations causal models. Applied Psychological Measurement, 14, 183-196.

Davis, J. H., Schoorman, F. D., \& Donaldson, L. (1997). Toward a stewardship theory of management. Academy of Management Review, 22, 20-47.

de Ruyter, K., de Jong, A., \& Wetzels, M. G. M. (2009). Antecedents and consequences of environmental stewardship in boundary-spanning b2b teams. Journal of the Academy of Marketing Science, 37, 470-487.

DEFRA. (2008). Framework for pro-environmental behaviours.

Do Paço, A., Alves, H., Shiel, C., \& Filho, W. L. (2013). A multi-country level analysis of the environmental attitudes and behaviours among young consumers. Journal of Environmental Planning \& Management, 56, 1532-1548.

Donaldson, T., \& Preston, L. E. (1995). The stakeholder theory of the corporation: Concepts, evidence, and implications. Academy of Management Review, 20, 65-91.

Dunlap, R. E., \& Van Liere, K. D. (1978). The "new environmental paradigm": A proposed measuring instrument and and preliminary results. Journal of Environmental Education, 9, 10-19. 
Dunlap, R. E., Van Liere, K. D., Mertig, A. G., \& Jones, R. E. (2000). Measuring endorsement of the new ecological paradigm: A revised nep scale. Journal of Social Issues, 56, 425-442.

Englis, B. G., \& Phillips, D. M. (2013). Does innovativeness drive environmentally conscious consumer behavior? Psychology \& Marketing, 30, 160-172.

European Commission. (2008). Communication from the commission to the european parliament, the council, the european economic and social committee and the committee of the regions on the sustainable consumption and production and sustainable industrial policy action plan. Retrieved June 30, 2014, from http://eurlex.europa.eu/LexUriServ/LexUriServ.do?uri=COM:2008:0397:FIN:EN:PDF

Fornell, C., \& Larcker, D. F. (1981). Evaluating structural equation models with unobservable variables and measurement error. Journal of Marketing Research, 18, 39-50.

Fox, M., Tost, L. P., \& Wade-Benzoni, K. A. (2010). The legacy motive: A catalyst for sustainable decision making in organizations. Business Ethics Quarterly, 20, 153-185.

Goldstein, N. J., Cialdini, R. B., \& Griskevicius, V. (2008). A room with a viewpoint: Using social norms to motivate environmental conservation in hotels. Journal of Consumer Research, 35, 472-482.

Grant, A. M., \& Wade-Benzoni, K. A. (2009). The hot and cool of death awareness at work: Mortality cues, aging, and self-protective and prosocial motivations. The Academy of Management Review, 34, 600-622.

Groesbeck, R. L. (2001). An empirical study of group stewardship and learning: Implications for work group effectiveness. Unpublished doctoral dissertation, State University, Blacksburg VA.

Hernandez, M. (2007). Stewardship: Theoretical development and empirical test of its determinants. Unpublished doctoral dissertation, Duke University, Durham NC.

Hernandez, M. (2008). Promoting stewardship behavior in organizations: A leadership model. Journal of Business Ethics, 80, 121-128.

Hernandez, M. (2012). Toward an understanding of the psychology of stewardship. Academy of Management Review, 37, 172-193.

Hong, S.-M., \& Faedda, S. (1996). Refinement of the hong psychological reactance scale. Educational \& Psychological Measurement, 56, 173.

Hulland, J. (1999). Use of partial least squares (pls) in strategic management research: A review of four recent studies. Strategic Management Journal, 20, 195.

Jöreskog, K. G., \& Sörbom, D. (2006). Lisrel 8.80 for windows. Lincolnwood, IL: Scientific Software International, Inc.

Kellstedt, P. M., Zahran, S., \& Vedlitz, A. (2008). Personal efficacy, the information environment, and attitudes toward global warming and climate change in the united states. Risk Analysis, 28, 113-126.

Kerr, N. L. (1996). "Does my contribution really matter?": Efficacy in social dilemmas. In W. Stroebe \& M. Hewstone (Eds.), European review of social psychology (Vol. 7, pp. 209-240). Chichester UK: Wiley.

Kim, Y., \& Choi, S. M. (2005). Antecedents of green purchase behavior: An examination of collectivism, environmental concern, and pce. Advances in Consumer Research, 32, 592-599.

Kinnear, T. C., Taylor, J. R., \& Ahmed, S. A. (1974). Ecologically concerned consumers: Who are they? Journal of Marketing, 38, 20-24.

Kollmuss, A., \& Agyeman, J. (2002). Mind the gap: Why do people act environmentally and what are the barriers to pro-environmental behavior? Environmental Education Research, 8, 239-260. 
Kouchaki, M., Smith-Crowe, K., Brief, A. P., \& Sousa, C. (2013). Seeing green: Mere exposure to money triggers a business decision frame and unethical outcomes. Organizational Behavior \& Human Decision Processes, 121, 53-61.

Krisjanous, J., Ashill, N. J., Eccarius, K., \& Carruthers, J. (2013). Scared stiff? The effectiveness of threat appeals in counseling services advertising to high-anxiety students. Psychology \& Marketing, 30, 874-890.

Lapinski, M. K., \& Rimal, R. N. (2005). An explication of social norms. Communication Theory, 15, 127-147.

Mathur, A. (1996). Older adults' motivations for gift giving to charitable organizations: An exchange theory perspective. Psychology \& Marketing, 13, 107-123.

Minton, A. P., \& Rose, R. L. (1997). The effects of environmental concern on environmentally friendly consumer behavior: An exploratory study. Journal of Business Research, 40, 37-48.

Moisander, J. (2007). Motivational complexity of green consumerism. International Journal of Consumer Studies, 31, 404-409.

Netemeyer, R. G., Bearden, W. O., \& Sharma, S. (2003). Scaling procedures: Issues and applications. Thousand Oaks, CA: Sage Publications, Inc.

Nolan, J. M., Schultz, P. W., Cialdini, R. B., Goldstein, N. J., \& Griskevicius, V. (2008). Normative social influence is underdetected. Personality and Social Psychology Bulletin, 34, 913-923.

OECD. (2011). Greening household behaviour: The role of public policy. Paris: OECD Publishing.

Pieters, R., Bijmolt, T., van Raaij, F., \& de Kruijk, M. (1998). Consumers' attributions of proenvironmental behavior, motivation, and ability to self and others. Journal of Public Policy \& Marketing, 17, 215-225.

Prothero, A., Dobscha, S., Freund, J., Kilbourne, W. E., Luchs, M. G., Ozanne, L. K., et al. (2011). Sustainable consumption: Opportunities for consumer research and public policy. Journal of Public Policy \& Marketing, 30, 31-38.

Ringle, C. M., Wende, S., \& Will, A. (2005). Smart pls 2.0 (beta). Hamburg, Germany.

Rippetoe, P. A., \& Rogers, R. W. (1987). Effects of components of protection-motivation theory on adaptive and maladaptive coping with a health threat. Journal of Personality and Social Psychology, 52, 596-604.

Roberts, J. A. (1996). Green consumers in the 1990s: Profile and implications for advertising. Journal of Business Research, 36, 217-231.

Staats, H., Harland, P., \& Wilke, H. A. M. (2004). Effecting durable change: A team approach to improve environmental behavior in the household. Environment and Behavior, 36, 341-367.

Steg, L., \& Vlek, C. (2009). Encouraging pro-environmental behaviour: An integrative review and research agenda. Journal of Environmental Psychology, 29, 309-317.

Stern, P. C. (2000). Toward a coherent theory of environmentally significant behavior. Journal of Social Issues, 56, 407-424.

Tenbrunsel, A. E., \& Messick, D. M. (1999). Sanctioning systems, decision frames, and cooperation. Administrative Science Quarterly, 44, 684-707.

Thøgersen, J. (2006). Norms for environmentally responsible behaviour: An extended taxonomy. Journal of Environmental Psychology, 26, 247-261.

Thøgersen, J., \& Crompton, T. (2009). Simple and painless? The limitations of spillover in environmental campaigning. Journal of Consumer Policy, 32, 141-163.

Thøgersen, J., \& Ölander, F. (2002). Human values and the emergence of a sustainable consumption pattern: A panel study. Journal of Economic Psychology, 23, 605-630. 
Urien, B., \& Kilbourne, W. (2011). Generativity and self-enhancement values in eco-friendly behavioral intentions and environmentally responsible consumption behavior. Psychology \& Marketing, 28, 69-90.

Vicente-Molina, M. A., Fernández-Sáinz, A., \& Izagirre-Olaizola, J. (2013). Environmental knowledge and other variables affecting pro-environmental behaviour: Comparison of university students from emerging and advanced countries. Journal of Cleaner Production, 61, 130-138.

Wade-Benzoni, K. A. (1999). Thinking about the future: An intergenerational perspective on the conflict and compatability between economic and environmental interests. American Behavioral Scientist, 42, 1393.

Wade-Benzoni, K. A. (2002). A golden rule over time: Reciprocity in intergenerational allocation decisions. Academy of Management Journal, 45, 1011-1028.

Wade-Benzoni, K. A. (2008). Maple trees and weeping willows: The role of time, uncertainty, and affinity in intergenerational decisions. Negotiation and Conflict Management Research, 1, 220-245.

Wade-Benzoni, K. A., Hernandez, M., Medvec, V., \& Messick, D. (2008). In fairness to future generations: The role of egocentrism, uncertainty, power, and stewardship in judgments of intergenerational allocations. Journal of Experimental Social Psychology, 44, 233-245.

Wade-Benzoni, K. A., \& Tost, L. P. (2009). The egoism and altruism of intergenerational behavior. Personality \& Social Psychology Review, 13, 165-193.

Wasserman, N. (2006). Stewards, agents, and the founder discount: Executive compensation in new ventures. Academy of Management Journal, 49, 960-976.

Webster Jr, F. E. (1975). Determining the characteristics of the socially conscious consumer. Journal of Consumer Research, 2, 188-196.

Wells, V. K., Ponting, C. A., \& Peattie, K. (2011). Behaviour and climate change: Consumer perceptions of responsibility. Journal of Marketing Management, 27, 808-833.

Wetzels, M., Odekerken-Schröder, G., \& van Oppen, C. (2009). Using pls path modeling for assessing hierarchical construct models: Guidelines and empirical illustration. MIS Quarterly, 33, 177-195.

White, K., MacDonnell, R., \& Ellard, J. H. (2012). Belief in a just world: Consumer intentions and behaviors toward ethical products. Journal of Marketing, 76, 103-118.

Whitmarsh, L., \& O'Neill, S. (2010). Green identity, green living? The role of proenvironmental self-identity in determining consistency across diverse proenvironmental behaviours. Journal of Environmental Psychology, 30, 305-314.

Witte, K. (1992). Putting the fear back into fear appeals: The extended parallel process model. Communication Monographs, 59, 329-349.

Wolburg, J. M. (2001). The "risky business" of binge drinking among college students: Using risk models for psas and anti-drinking campaigns. Journal of Advertising, 30, 23-39.

Zeithaml, V. A., Berry, L. L., \& Parasuraman, A. (1996). The behavioral consequences of service quality. the Journal of Marketing, 31-46.

Zhao, X., Lynch Jr, J. G., \& Chen, Q. (2010). Reconsidering baron and kenny: Myths and truths about mediation analysis. Journal of Consumer Research, 37, 197-206. 


\section{Table 1}

\section{Study 1: Measures and Items}

\begin{tabular}{lr}
\hline \multicolumn{1}{c}{ Item } & SL \\
\hline Consumer Environmental Stewardship (CENS) & .81 \\
I feel a personal sense of responsibility for the environment. & .77 \\
I feel accountable for the environmental impact of my purchases. & .68 \\
I think it is inappropriate, for me as a single person, to buy products & \\
without considering the environmental impact of them. & .75 \\
When searching for a product I should seek a balance between its costs & .77 \\
and its impact on the environment. & .71 \\
I am willing to make personal sacrifices for the good of the & .81 \\
environment. & .77 \\
I carry responsibility for the environmental impact of my purchases on & .71 \\
society. & \\
I need to help maintaining a green environment for society. & \\
In my service to society I should balance short term personal goals with & .77 \\
long-term environmental goals. & \\
I feel responsible for the environmental impact of my purchases on & .81 \\
future generations. & \\
I need to help maintaining a green environment for future generations. & .82
\end{tabular}

Perceived Consumer Effectiveness (PCE)

$.87 \quad .62$

It is worthless for the individual consumer to do anything about $\quad .76$ pollution. $^{\text {a }}$

Since one person cannot have any effect upon natural resource problems $\quad .84$ it does not make any difference what I do. ${ }^{\text {a }}$

Each consumer's behavior can have a positive effect on society by

purchasing products sold by socially responsible companies.

Even as a single person one can have an effect on pollution.

Affinity with Future Generations (AFG)

I feel empathic toward future generations that will be living in my home region.

I am able to imagine future generations that will be living in my home region.

I feel an affinity toward future generations that will be living in my home region.

I can identify with future generations that will be living in my home region.

\section{Norms among the Current Generation (NCG)}

How often do you think that the current residents of your home region... ...try to conserve valuable resources for the sake of the environment?

...try to recycle their garbage?

...try to choose the environmentally friendly alternative if available? purchase? 
How often do you think that the residents that lived in your home region

a few decades ago...

...tried to conserve valuable resources for the sake of the environment? $\quad .77$

...tried to recycle their garbage?

...tried to choose the environmentally friendly alternative if available? $\quad .86$

...tried to discover the environmental effects of products prior to purchase?

\footnotetext{
${ }^{\mathrm{a}}$ Items were reversely scored before analyses because they are negatively framed.

Note: SL = Standardized Loading; CR = Composite Reliability; AVE = Average Variance Extracted.
} 


\section{Table 2}

\section{Study 1: Items Pro-environmental Behavior}

\section{Items}

\section{Conservation}

Do you have lights burning in non-occupied rooms? Is your television set on "off" instead of on "standby"?

Do you save dirty laundry until you can load your washing machine fully?

Do you close the faucet while brushing your teeth?

Do you use alternatives for the car (or motorbike) to travel distances less than $5 \mathrm{~km}$ ?

Do you eat a dinner without meat?

Do you eat organically grown food?

Do you bring your own shopping bag from home, when you go shopping for groceries?

Do you refuse plastic bags or wrappings of shopkeepers for environmental reasons?

Are you inclined to repair products or have them repaired instead of buying them new?

\section{Purchasing}

Do you choose the environmentally friendly alternative if one of the same price is available?

Do you choose the environmentally friendly alternative regardless of price?

Do you try to discover the environmental effects of products prior to purchase?

Do you buy environmentally friendly detergents?

Do you buy products not tested on animals?

Do you buy recycled paper products?

Do you buy organically grown fruit and vegetables?

\section{Recycling}

Do you recycle paper?

Do you recycle glass?

Do you recycle plastics?

Do you recycle metals?

\section{Environmental activism}

Do you support environmental pressure groups?

42.30

43.02

56.99

45.15

15.79

14.74

39.40

76.20

38.45

160.48

30.35

.048

.130

.363

210.47

.263

.514

286.05

.326

170.41

.224

.474

125.14

.174

.162

.419

114.89

.105

.405

.327

Do you consider green issues in your voting behavior?

Do you write about green issues in newspapers or on internet fora/blogs?
128.93

255.52

.302

.551

26.13

.041 .206 
Do you boycott companies that are not environmentally responsible?

\section{Information Seeking}

Do you compare package label information about the environmental safety of the product and/or package while you are in the grocery store?

Do you actually pay attention to advertisements about environmentally friendly products?

Do you talk to people close to you about various environmentally friendly products or activities?

${ }^{*}$ All $\mathrm{F}$ scores and $\beta$ values are significant at $p<.01$ 
Table 3

Study 1: Intercorrelations

\section{Construct}

1. 2. 3. $4 . \quad 5.6$. 6.

1.Pro-environmental behavior

2. Consumer Environmental Stewardship (CENS) $\quad .76 \quad .77$

3. Perceived Consumer Effectiveness (PCE) $\quad .39 \quad .52 \quad .79$

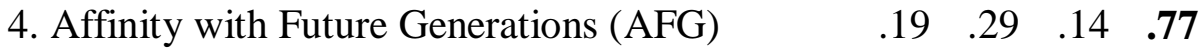

5. Norms among the Current Generation (NCG) $\quad \begin{array}{lllll}14 & .19 & .05 & .17 & \mathbf{8 0}\end{array}$

$\begin{array}{lllllll}\text { 6. Norms among the Previous Generation (NPG) } & .18 & .16 & .07 & .09 & .19 & \mathbf{. 8 1}\end{array}$

Notes: $\mathrm{N}=589$, Square root of average variance extracted (AVE) on the diagonal where applicable. 
Figure 1: Results Conceptual Model

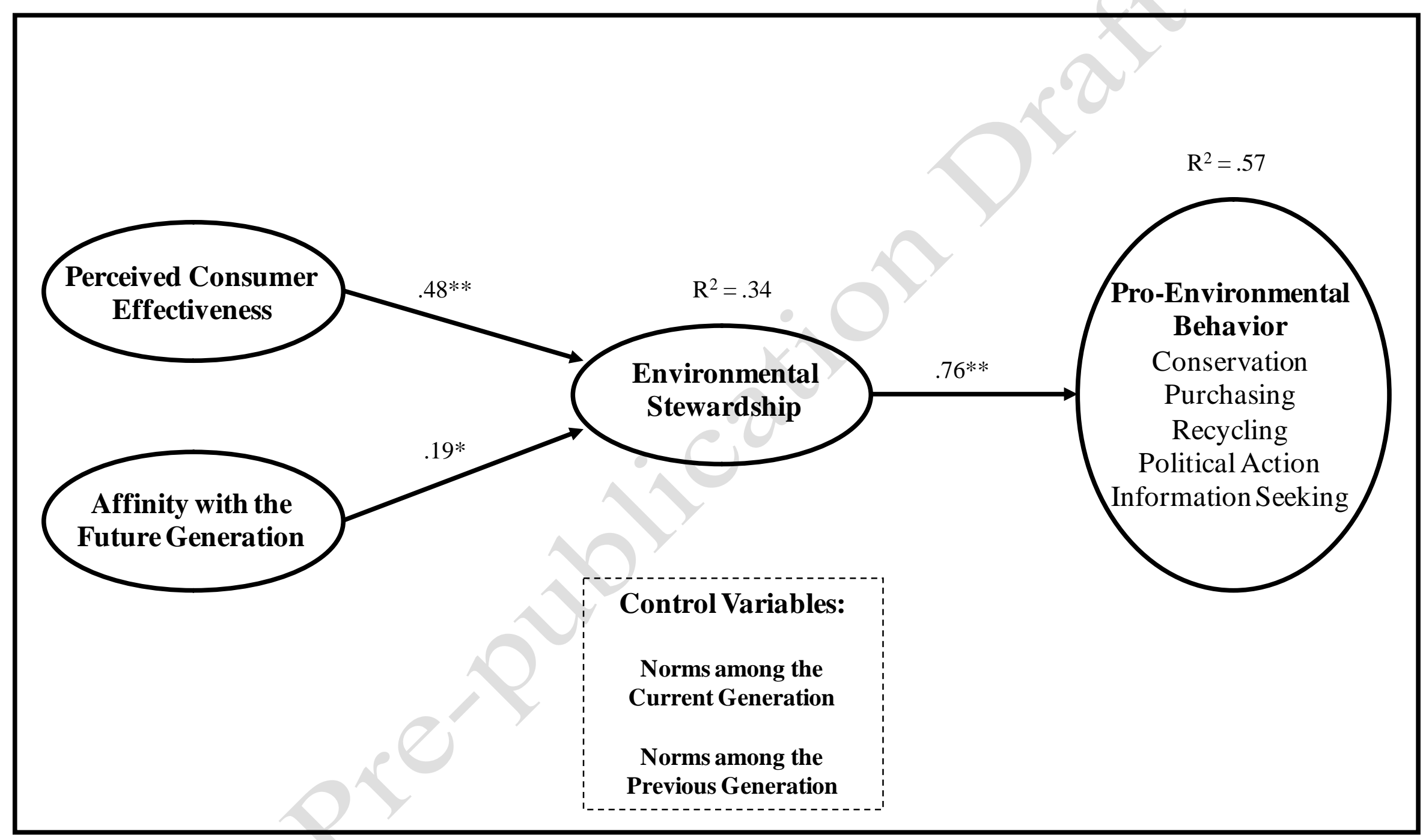

${ }^{*} p<.05 ;{ }^{* *} p<.01$ (two-tailed). 
Figure 2: Visual Representation of Interaction between AFG and PCE for Study 2

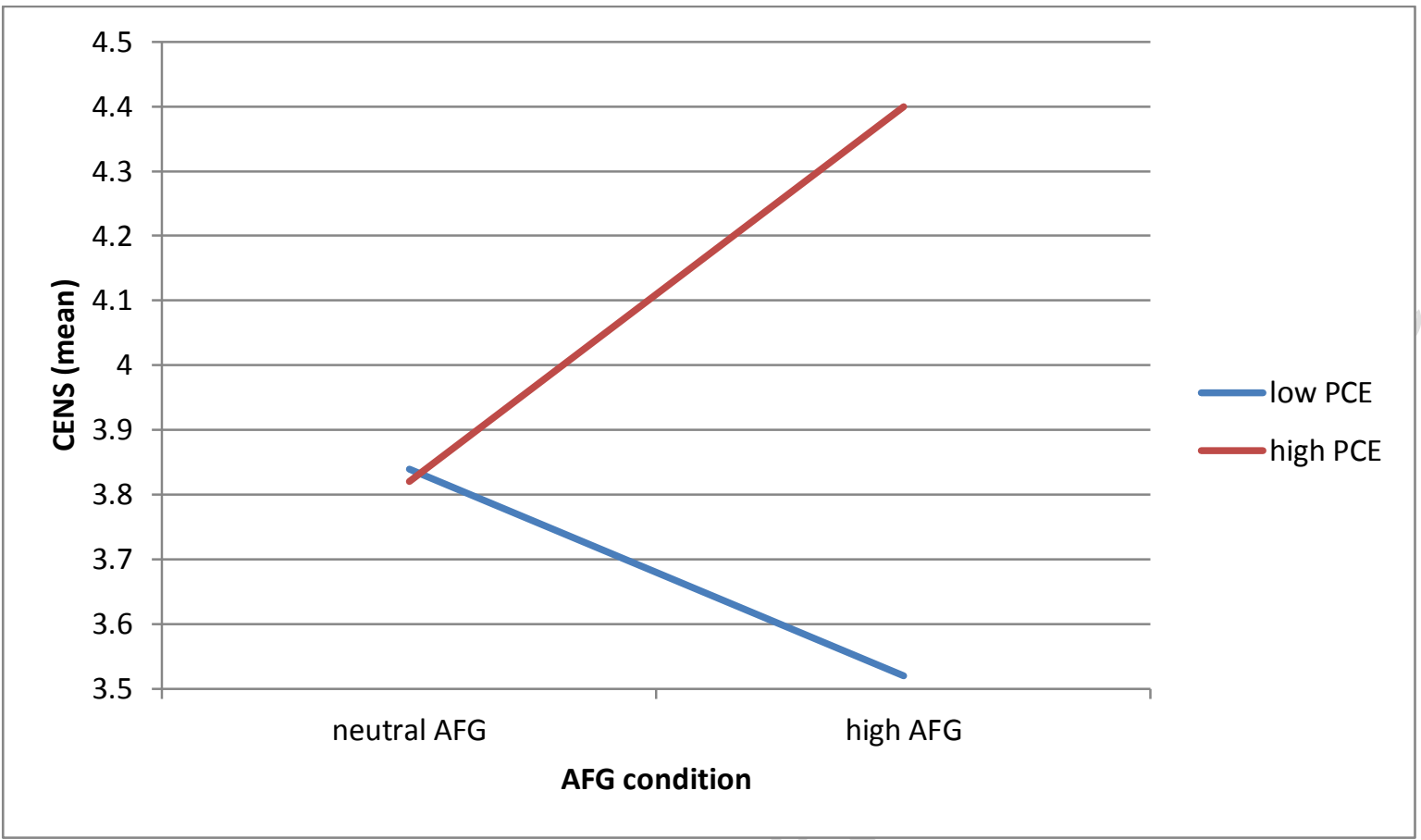


Figure 3: Visual Representation of Interaction between AFG and PCE for Study 3

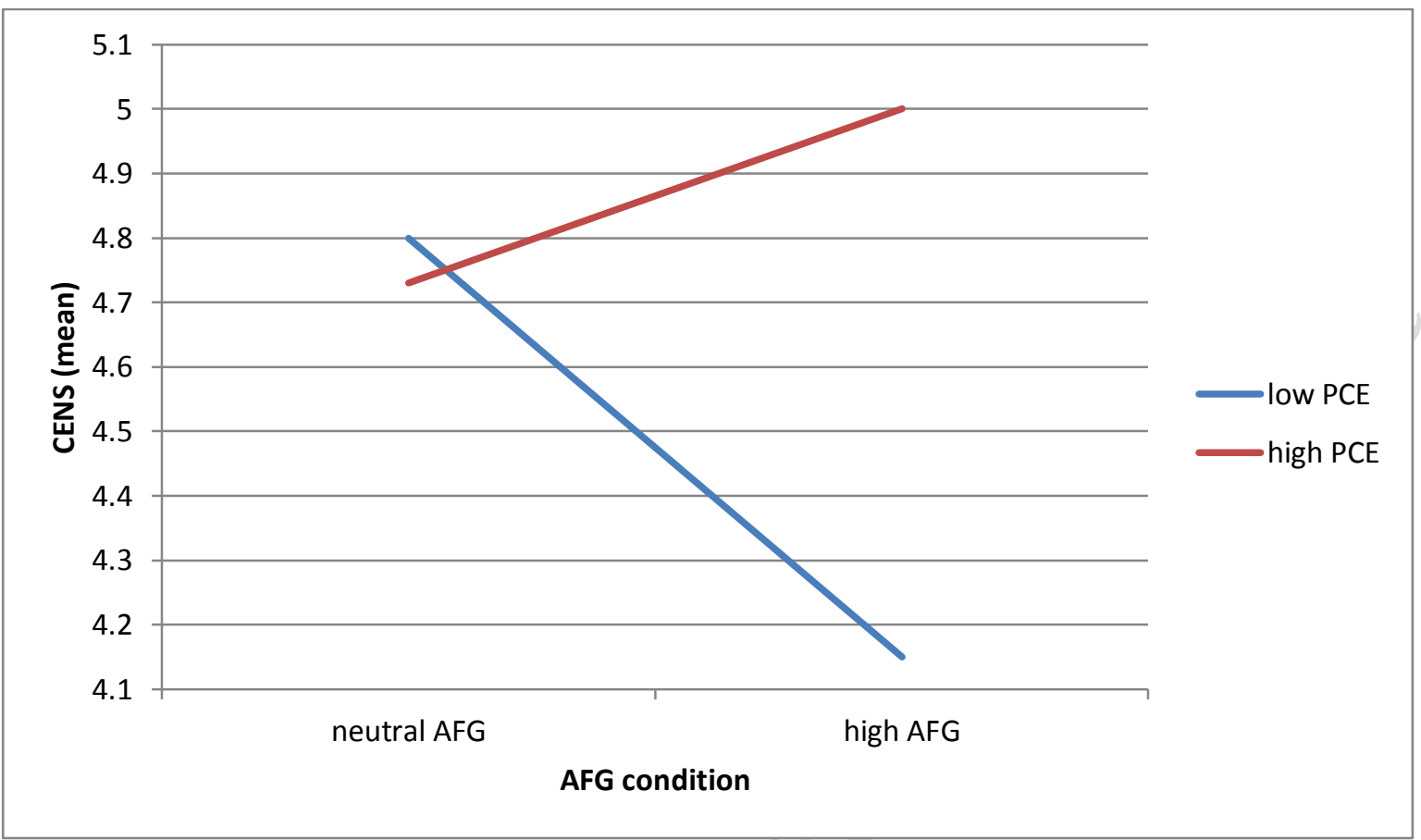


Figure 4: Visual Representation of Interaction between AFG and PCE for Study 4

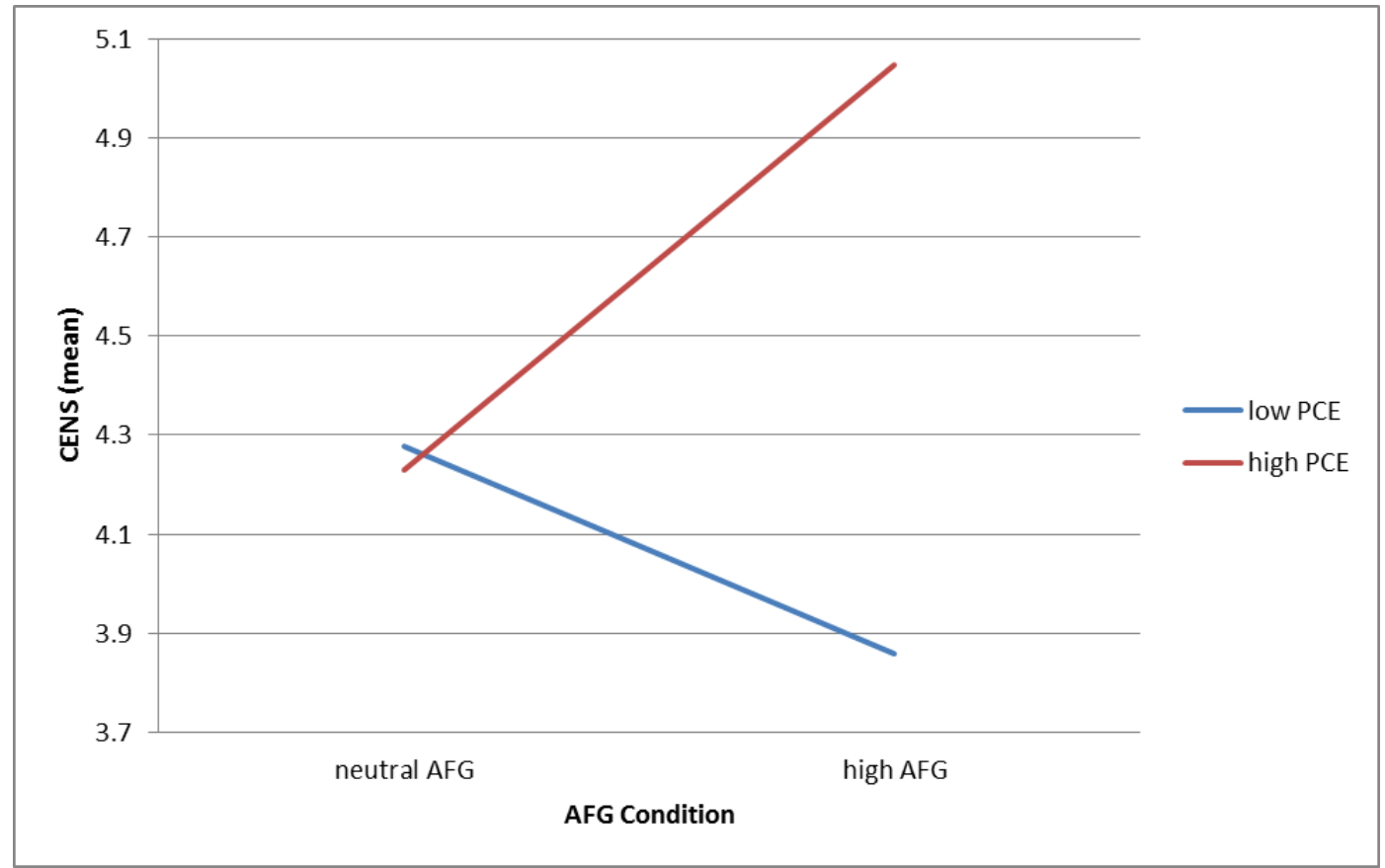


Appendix A: Stimuli for Affinity with Future Generations (AFG)

Neutral AFG Condition Study 2 \& 3:

Please think about your favorite brand. Write a short story about your favorite brand and the reasons why you like to consume this brand. Think about your relationship with the brand. (In case you have multiple favorite brands choose one to write the story about).

Please write down everything that comes to your mind. Please spend at least 5 minutes on this assignment and try to write a story of 10 sentences or more.

High AFG Condition Study 2 \& 3:

Please think about your own children and grandchildren. Write a short story about how they grow up and your role as a (grand)parent. Think about your relationship with them. (In case you do not have children or grandchildren imagine what it would be like).

Please write down everything that comes to your mind. Please spend at least 5 minutes on this assignment and try to write a story of 10 sentences or more. 


\title{
Appendix B: Stimuli for Perceived Consumer Effectiveness (PCE)
}

\author{
High PCE Condition:
}

\section{Date}

From our reporter in Brussels

In a recent report, the Institute for Sustainable Consumption (ISC) proclaims that consumers play a key role in battling climate change. A reduction in $\mathrm{CO}_{2}$ emissions is needed more quickly than industry can achieve. Disagreements and diverging interests prevent companies from taking the necessary action. In contrast, consumers show a uniform willingness to reduce the burden they put on the environment. In combination with their strength in numbers, this means consumers' potential impact is big. Looking at EU emissions alone, ISC's conservative estimate shows that $75 \%$ of energy use and $\mathrm{CO}_{2}$ emissions are caused directly or indirectly by consumers. ISC's recent analyses show that measures directed at consumers could reduce total EU emissions by over 8\% in the next ten years. This amount is larger than the combined emissions from a majority of the largest-emitting EU industrial sectors. Based on these results, ISC concluded that government initiatives for lowering emissions should focus on individual consumers. Government institutions can help consumers to change their behavior voluntarily and to seek low-carbon products and services. Consumers can reduce emissions in the least expensive way and have an immediate impact that can be sustained.

\section{Low PCE Condition:}

\section{Date}

From our reporter in Brussels

In a recent report, the Institute for Sustainable Industry (ISI) proclaims that industry plays a key role in battling climate change. A reduction in $\mathrm{CO}_{2}$ emissions is needed more quickly than consumers can achieve. Disagreements and diverging interests prevent consumers from taking the necessary action. Consumers lack a uniform willingness to reduce the burden they put on the environment. In contrast, industry is more organized. In combination with its strength in size, this means that industry's potential impact is big. Looking at EU emissions alone, ISI's conservative estimate shows that $75 \%$ of energy use and $\mathrm{CO}_{2}$ emissions are caused directly or indirectly by industry. ISI's recent analyses show that measures directed at industry could reduce total EU emissions by over $8 \%$ in the next ten years. This amount is larger than the combined emissions from a majority of EU consumers. Based on these results, ISI concluded that government initiatives for lowering emissions should focus on the industrial sector. Government institutions can help industrial companies to change their practices voluntarily and to seek low-carbon solutions and opportunities. Industry can reduce emissions in the least expensive way and have an immediate impact that can be sustained. 